\title{
Post-fledging movements, mortality and migration of juvenile northern gannets
}

\author{
Jude V. Lane ${ }^{1, *}$, Christopher J. Pollock ${ }^{1}$, Ruth Jeavons ${ }^{1}$, Maggie Sheddan ${ }^{2}$, \\ Robert W. Furness ${ }^{3}$, Keith C. Hamer ${ }^{1}$ \\ ${ }^{1}$ School of Biology, University of Leeds, Leeds LS2 9JT, UK \\ ${ }^{2}$ Scottish Seabird Centre, North Berwick EH39 4SS, UK \\ ${ }^{3}$ MacArthur Green, Glasgow G20 6NT, UK
}

\begin{abstract}
Studying the at-sea movements and behaviour of juvenile seabirds is logistically challenging, but new technologies now allow tracking birds on their first migration, giving a more complete picture of population-level spatial ecology. We investigated the post-fledging migration of juvenile northern gannets Morus bassanus from the world's largest colony, at Bass Rock, Scotland. We first examined the movements and survival of 38 juveniles over their initial days at sea with GPS precision for up to $53 \mathrm{~d}$ post-fledging. We then compared their migration journeys with those of 35 adults tracked with geolocators. Almost one-third of juveniles died within 2 mo of leaving the colony, and this mortality was often associated with apparent uncertainties in their direction of migration, including marked, abrupt and often repeated changes in bearing within the North Sea. Both juveniles and adults then migrated as far as the Canary Current Large Marine Ecosystem (CCLME) off the Atlantic coast of West Africa, initially taking both clockwise and counter-clockwise routes around the UK. Juveniles covered a distance each day similar to that of adults, but they reached the CCLME much more quickly, mainly because they travelled more directly, staying close to the coast throughout most of their migration, whereas adults additionally spent long periods over relatively restricted areas of ocean further offshore. The CCLME is a hotspot of unregulated fishing activity, and our findings highlight the importance of this region across different age-classes of birds, echoing previous calls that the regional strengthening of marine conservation should be a high priority.
\end{abstract}

KEY WORDS: Mortality $\cdot$ Migration $\cdot$ GPS tracking $\cdot$ Northern gannet $\cdot$ Morus bassanus $\cdot$ Juvenile

\section{INTRODUCTION}

Young animals typically have much higher mortality than adults, and understanding this difference is fundamental to the study of population structure, size and dynamics (Charlesworth 1980, Stearns 1992, Genovart et al. 2018). The main hypothesis invoked to explain higher mortality in early life is that a lack of experience and learning, combined with physical immaturity, results in poor proficiency in skills such as foraging and predator avoidance (Sullivan 1989,

\footnotetext{
*Corresponding author: j.lane@leeds.ac.uk
}

Daunt et al. 2007, Riotte-Lambert \& Weimerskirch 2013). In many species, an additional major challenge in early life is completing an autumnal migration to regions with more favourable climates and higher winter food availability (Alerstam et al. 2003, Rotics et al. 2016, Breed et al. 2018, Sergio et al. 2019).

Juveniles make autumn migrations along routes and to destinations of which they have no prior experience, with those that make the journey alone having to rely solely on innate navigation capabilities

() The authors 2021. Open Access under Creative Commons by Attribution Licence. Use, distribution and reproduction are unrestricted. Authors and original publication must be credited. 
that may be less well developed than in adults (Mueller et al. 2013, Sergio et al. 2019). Inferior navigation can lead to less efficient travel, as seen in juvenile Scopoli's shearwaters Calonectris diomedea, whose first autumn migrations are longer and more sinuous than those of adults (Péron \& Grémillet 2013) and in golden eagles Aquila chrysaetos, which transition from vector-oriented migrations (travelling north-south) as juveniles to goal-oriented migrations (travelling to a previously visited destination) as adults (Miller et al. 2016). Understanding the movements of naïve individuals has been identified as a priority area for marine research due to a need to better understand how juveniles disperse from natal areas, make use of different marine habitats and overlap with potential threats (Hazen et al. 2012, Riotte-Lambert \& Weimerskirch 2013). Studying the at-sea movements and behaviour of juvenile seabirds remains logistically challenging, but new technologies now allow tracking of birds on their first migration, allowing a more complete picture of populationlevel spatial ecology (de Grissac et al. 2016, Afán et al. 2019, Borrmann et al. 2021).

Northern gannets Morus bassanus (hereafter termed gannets) typically breed for the first time aged 5 yr (Nelson 2002) and forage in neritic waters (Wakefield et al. 2015). At the end of the breeding season, adults at European colonies migrate south as far as the Atlantic coast of West Africa (Kubetzki et al. 2009, Deakin et al. 2019, Grecian et al. 2019), with evidence of oriented chain migration (where populations move uniformly southwards) by birds from different colonies (Fort et al. 2012). Juveniles are independent of their parents after fledging (Nelson 2002) and therefore need to learn critical foraging, flight and navigation skills without parental guidance, possibly contributing to high mortality during their first year (Wanless et al. 2006). They may remain on the water for several days post-fledging while they lose mass and gain sufficient strength to take off from the water surface (Wanless \& Okill 1994), yet little is known about their subsequent movements or behaviour. Ring recoveries, together with tracks of 4 juveniles from a colony in the English Channel, suggest that like adults they may migrate as far south as West Africa (Nelson 2002, Grémillet et al. 2015), while juvenile gannets tracked from 2 colonies in northeast Canada dispersed widely and overwintered from the mid-Atlantic region to the Gulf of Mexico (Spiegel et al. 2017). However, the development of directed movements, migration routes and speeds of travel have not previously been examined. Here we investigate the post-fledging movements and migration of juvenile gannets from the world's largest colony (Murray et al. 2014), at Bass Rock, Scotland (56 6' N, $\left.2^{\circ} 36^{\prime} \mathrm{W}\right)$. We tracked birds with GPS precision for up to $53 \mathrm{~d}$ post-fledging, allowing us first to examine the movements and survival of juveniles over their initial days at sea, and then to compare their migration journeys with those of adults tracked with geolocators from the same colony, specifically examining migration routes and speeds of travel.

\section{MATERIALS AND METHODS}

\subsection{Sampling of birds}

Forty-two juvenile gannets that had left their nest sites but were still at the colony were captured using a $6 \mathrm{~m}$ telescopic pole fitted with a metal noose or by hand on 5 October $2018(\mathrm{n}=21)$ or 20 September 2019 ( $\mathrm{n}=21$ ), prior to departing to sea. Most gannet chicks at Bass Rock currently fledge in mid-to-late September each year (2-3 wk later than in the 1960s; Nelson 2002). Hence, sampling was around the peak of fledging in 2019 and slightly after the peak in 2018. Each bird was weighed (to the nearest $25 \mathrm{~g}$ using a spring balance) and fitted with a metal British Trust for Ornithology (BTO) ring inscribed with a unique identification number. A solar powered Argos GPS-platform terminal transmitter (GPS-PTT; Microwave Telemetry), weighing $45 \mathrm{~g}$ (2018) or $30 \mathrm{~g}$ (2019) was then attached to the upper side of the 3 central tail feathers using Tesa () tape and cable ties (additional weight $=4 \mathrm{~g}$ ). Each GPS-PTT was programmed to record a GPS location once an hour between 06:00 and 20:00 h, and locations were relayed to the Argos satellite system every $24 \mathrm{~h}$. Handling time of birds was no longer than $20 \mathrm{~min}$, after which time birds were released at the colony. The weight of the GPSPTT in each case was $<2 \%$ of body mass, which was considered sufficiently small to minimise risk of adverse effects (Phillips et al. 2003, Cleasby et al. 2015, Bodey et al. 2018).

Adult gannets attending a separate sample of chicks at Bass Rock during July and August 2018 ( $\mathrm{n}=26)$ and 2019 ( $\mathrm{n}=36$ ) were caught using the same method as juveniles, weighed and fitted with a metal BTO ring. A combined geolocation-immersion logger (Mk 3006 British Antarctic Survey, n = 58; Initgeo C65, Migrate Technology Ltd, $\mathrm{n}=4$ ) attached with 2 cable ties to a plastic ring was then fitted to the tarsus of each bird. The total mass of the attachment was $<10 \mathrm{~g}(\sim 0.3 \%$ of adult body mass). On release all birds returned to their 
chick and resumed normal behaviour almost immediately. Geolocators were then recovered (60\%) between April and August in the years following device deployment.

\subsection{Track reconstruction}

Argos locations from GPS-PTTs on juveniles were filtered by speed and location class (LC) to remove erroneous locations using the $\mathrm{R}$ package 'argosfilter' (Freitas 2012, Langston et al. 2013; speeds $>25 \mathrm{~ms}^{-1}$ and LC $\mathrm{Z}$ were removed). GPS (precise to $<100 \mathrm{~m}$ ) and Argos PTT location classes 3, 2, 1, A and B (precision $<250$ to $>1500 \mathrm{~m}$; Argos 2016) were then combined to reconstruct movements. All locations with duplicated dates and times were screened, and only the duplicate with greater precision was retained. A total of 15834 valid locations was received of which 6780 (43\%) were GPS and 9054 (57\%) were ARGOS PTT. GPS locations were not obtained overnight, but average speeds between 20:00 and 06:00 h indicated that, like adults (Hamer et al. 2000, Furness et al. 2018), juveniles did not fly at night. Hence, overnight travel speeds were removed from the analysis.

Geolocators on adults recorded light intensity and time, which were used to generate a location at dawn and dusk each day using the R package 'GeoLight' (Lisovski \& Hahn 2012). Data from 21 d before and $14 \mathrm{~d}$ after the autumn equinox were removed due to unreliable estimates of latitude during this period. Each location was then re-estimated using an iterative forward-step selection framework to create a cloud of 2000 possible locations in each case. Locations within each cloud of points were weighted according to daily median sea surface temperature (SST) recorded by the logger and daily mean National Oceanic and Atmospheric Administration (NOAA) SST data at $0.25^{\circ}$ resolution (Reynolds et al. 2007, Physical Sciences Division 2019) using the R package 'probGLS' (Merkel et al. 2016). The most probable track was then obtained using the geographic median position from each weighted location cloud. A test of this approach using data for 2 species of albatross in the Southern Ocean indicated a median error of 145-185 km compared to locations obtained using GPS (Merkel et al. 2016). Nonetheless, while the lower precision of the geolocator data may have resulted in greater variance in estimates of daily distances travelled by adults than by juveniles in our study, it would not have biased the comparison of mean distances travelled.

\subsection{Juvenile fledging and survival at sea}

Juveniles were considered to have fledged once GPS data identified them as being $\geq 0.5 \mathrm{~km}$ from the colony, with subsequent flight indicated by a speed of $\geq 3.5 \mathrm{~km} \mathrm{~h}^{-1}$ between consecutive GPS locations (Wakefield et al. 2013). Birds were considered to have died if: (1) GPS data indicated they did not fledge or take flight from the water once fledged; (2) subsequent GPS data indicated one or more complete days of inactivity with no movement (if on land) or only slow drifting of location (if at sea) before the signal was lost, and/or; (3) they were recovered postmortem by a member of the public. In contrast, occasions when the signal was lost suddenly during normal activity of the bird were assumed to have resulted from failure of the tag or attachment. All birds recovered post-mortem had shown no movement or slow drifting at the coast for at least a complete day prior to the final data transmission.

\subsection{Migration patterns of juveniles and adults}

We investigated the development of flight activity among juveniles by estimating mean hourly displacement per day once birds were first airborne, calculated as the sum of straight-line distances between consecutive GPS locations during daylight hours divided by the number of hours. We then compared the migration of adults and juveniles by inspecting maps of their journeys. To compare migration parameters (time in days, distance in $\mathrm{km}$, etc.), we used the subset of birds of each age-class that were tracked beyond the Strait of Gibraltar $\left(36.20^{\circ} \mathrm{N}\right)$ to the coast of West Africa. This ensured that our comparison was not confounded by differences in the migration goals of birds (Kubetzki et al. 2009, Grecian et al. 2019). In each case, the time taken in migration was estimated in days from the first day birds took flight from the water (juveniles) or from when they left the colony for the winter (adults) until their first day south of the Strait of Gibraltar. Adult departure dates were determined from immersion data indicating when the bird last spent time at the colony overnight (birds do not fly in darkness, so an absence of immersion in salt water overnight indicated time spent on land, presumably at the colony). Departure was then confirmed from geolocator data after 6 October each year (see Section 2.2 above), indicating the bird was always remote from the colony at both dawn and dusk each day. The total distance travelled was calculated as the cumulative 
distance between each consecutive location. To compare distances and travel speeds of juveniles and adults, the combined GPS-PTT data for juveniles were subsampled to include only the first and last location recorded each day. Daily distance travelled $\left(\mathrm{km} \mathrm{d}^{-1}\right)$ was then estimated by dividing the total distance travelled by the number of travel days. We used a general linear mixed model (LMM) using restricted maximum-likelihood (REML), specified in the R-3.5.1 package 'nlme' (R Core Team 2016, Pinheiro et al. 2018) to test for the effects of travel direction, age-class, year and their interactions on the distances travelled per day and the number of days spent travelling to the Strait of Gibraltar. Models included bird identity as a random effect to account for repeated measures. The number of days spent travelling was right skewed and so was log-transformed prior to analysis. Model selection was based on Akaike's information criterion adjusted for small sample size $\left(\mathrm{AIC}_{\mathrm{c}}\right)$, with the top model $\left(\Delta \mathrm{AIC} \mathrm{C}_{\mathrm{c}}>2\right)$ refitted to obtain p values in each case (Burnham \& Anderson 2002). All values are presented as mean \pm SD.

\section{RESULTS}

\subsection{Collection of data}

We tracked 38 juveniles for up to $53 \mathrm{~d}$ post-fledging $(\mathrm{n}=17$ in 2018, 21 in 2019; 4 tags or attachments failed within $3 \mathrm{~d}$ of deployment or before the bird fledged in 2018 and so did not provide useful data). There was no difference between years in the number of days juveniles were tracked at sea (in 2018, 25 $\pm 13.5 \mathrm{~d}, \mathrm{n}=17$; in $2019,30 \pm 14.5 \mathrm{~d}, \mathrm{n}=21 ; F_{1,36}=1.3$, $\mathrm{p}=0.3$ ) or the average distance travelled per day (in $2018,59.2 \pm 49.3 \mathrm{~km}, \mathrm{n}=17$; in 2019, $61.2 \pm 44.2 \mathrm{~km}$, $\left.\mathrm{n}=21 ; F_{1,36}=0.02, \mathrm{p}=0.9\right)$. We obtained geolocator data from 35 adults (in 2018-2019, $\mathrm{n}=21$; in 20192020, $n=14$ ), with data obtained from 7 individuals in both years. Mean departure dates of adults were similar each year (21 September in 2018, 25 September in 2019), corresponding broadly with the peak in chick fledging, although the latest recorded adult departure was not until 15 October each year. Of the 38 juveniles tracked, 11 birds (29\%) died before completing migration (6 in 2018, 5 in 2019; see Table S1 in Supplement for details; www.int-res.com/ articles/suppl/m671p207_supp.pdf), 12 birds (44\% of survivors) were tracked to the Canary Current Large Marine Ecosystem (CCLME) off the coast of West Africa, and 15 birds (56\% of survivors) were travelling rapidly at intermediate locations between Bass
Rock and the Strait of Gibraltar when their signal was lost, presumably due to failure of the transmitter or attachment (Fig. 1). There was no difference in pre-fledging body masses between the 11 birds considered to have died before completing migration $(3348 \pm 251 \mathrm{~g})$ and the remaining 27 birds (3373 \pm $\left.362 \mathrm{~g} ; t_{36}=0.2, \mathrm{p}=0.8\right)$. Of the 35 adults tracked, 23 $(66 \%)$ travelled as far as West Africa and 12 (34\%) overwintered at intermediate locations, with overall movements ranging as far north as the southern Norwegian Sea and as far west as the mid-Atlantic ridge (Fig. 1).

\subsection{Initial movements of juveniles at sea}

After fledging, one juvenile died without ever becoming airborne from the sea, while the remaining 37 birds next took flight after 2-9 d (mean = $4 \mathrm{~d}$ ), then in most cases spent a further 3-4 d interspersing short flights with periods resting on the water. Consequently, the mean hourly displacement of juveniles during hours of daylight increased significantly from a mean of $13.5 \mathrm{~km}(\mathrm{SD} \pm 9.26)$ during the initial $5 \mathrm{~d}$ after first becoming airborne from the water to $21.1 \pm 11.3 \mathrm{~km}$ during the following $5 \mathrm{~d}$ (paired $t$-test; $t_{25}=2.70, \mathrm{p}=$ $0.012 ; 26$ birds had sufficient data to calculate speeds accurately over this period) then changed little thereafter $(19.4 \pm 12.6 \mathrm{~km}$ over the following $5 \mathrm{~d})$.

\subsection{Direction, speed and directness of travel}

Juveniles and adults migrated in both clockwise and counter-clockwise directions around the UK (juveniles: 17 clockwise, 16 counter-clockwise; adults: 17 clockwise, 8 counter-clockwise). However, juveniles stayed close to the coast except when south of Ireland and crossing the Bay of Biscay $(75 \%$ of all locations for juveniles were $\leq 15 \mathrm{~km}$ from the nearest coastline), whereas adults were apparently located further offshore at all stages of migration, including over winter (Figs. 1 \& 2).

Despite initial slow travel, on average juveniles that were tracked to the Strait of Gibraltar covered distances per day very similar to those of adults once they had first become airborne from the sea (334 \pm 136 and $347 \pm 162 \mathrm{~km}$, respectively; $F_{1,19}=0.15, \mathrm{p}=$ $0.7)$. There was no significant difference between years or directions of travel (clockwise or counterclockwise) in distances travelled per day by adults or juveniles (Table S2 \& S3; p > 0.1 in each case). Despite travelling similar distances to adults per day, 

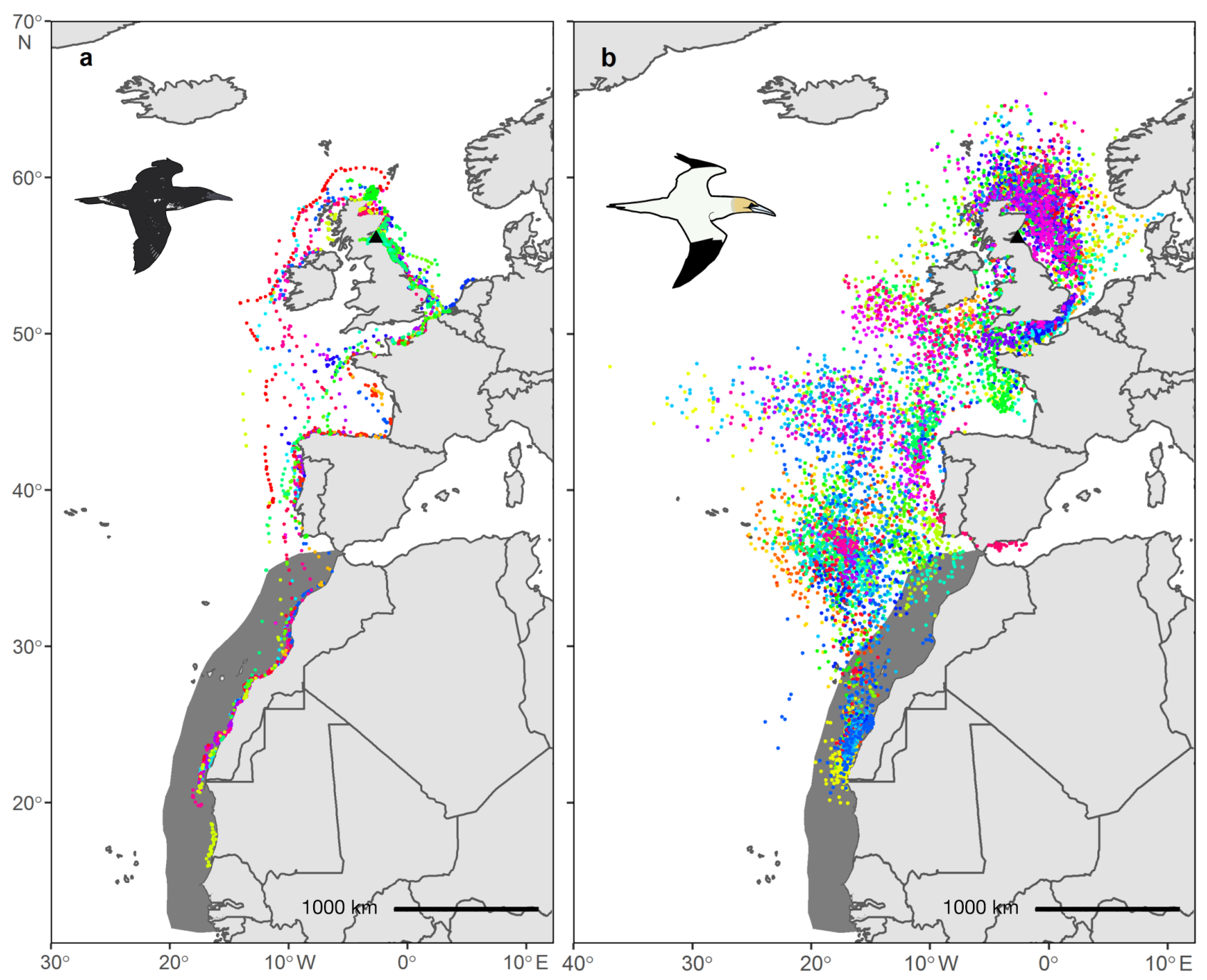

Fig. 1. (a) GPS locations of 41 juvenile gannets tracked from Bass Rock (black triangle) between September and November 2018 and 2019; (b) GLS locations of 35 adults tracked from Bass Rock between September and January 2018-19 and 2019-20. Individual birds identified by colour. Shaded area in (a) and (b) shows the Canary Current Large Marine Ecosystem

juveniles took many fewer days than adults to pass the Strait of Gibraltar (juveniles, $22 \pm 10$ d; adults, 68 $\left.\pm 32 \mathrm{~d}_{i} F_{1,23}=52.7, \mathrm{p}<0.001\right)$. This difference in journey times was mainly because, in addition to periods of rapid direct travel, adults apparently spent longer periods (more than a month in some cases) over relatively restricted areas of ocean en route to the CCLME whereas juveniles did not. In particular, adults appeared to spend time northeast of Bass Rock and in an area of ocean roughly between Iberia, Madeira and the Azores Islands (Figs. 1 \& 2). Adults also took significantly fewer days to reach the Strait of Gibraltar in 2018 than in 2019 (Table $1 ; F_{1,23}=$ 15.47, $\mathrm{p}<0.001)$, but the direction of travel had no significant effect on the number of days taken by juveniles or adults, and there was no significant dif- ference between years in the number of days taken by juveniles (Table $\mathrm{S} 2 \& \mathrm{~S} 3$ ).

\subsection{Juvenile mortality}

Of the 11 juveniles that died during migration, 4 apparently failed to navigate effectively, heading west from Bass Rock and either circling the Firth of Forth for several days or, in one case, heading overland before dying. A further 5 birds had uncertain migration routes characterised by multiple abrupt changes in direction (Fig. 3). Such apparently flawed migration did not necessarily result in birds dying, but overall, mortality was higher among such birds (10 of 21 individuals) than among those that migrated without any 

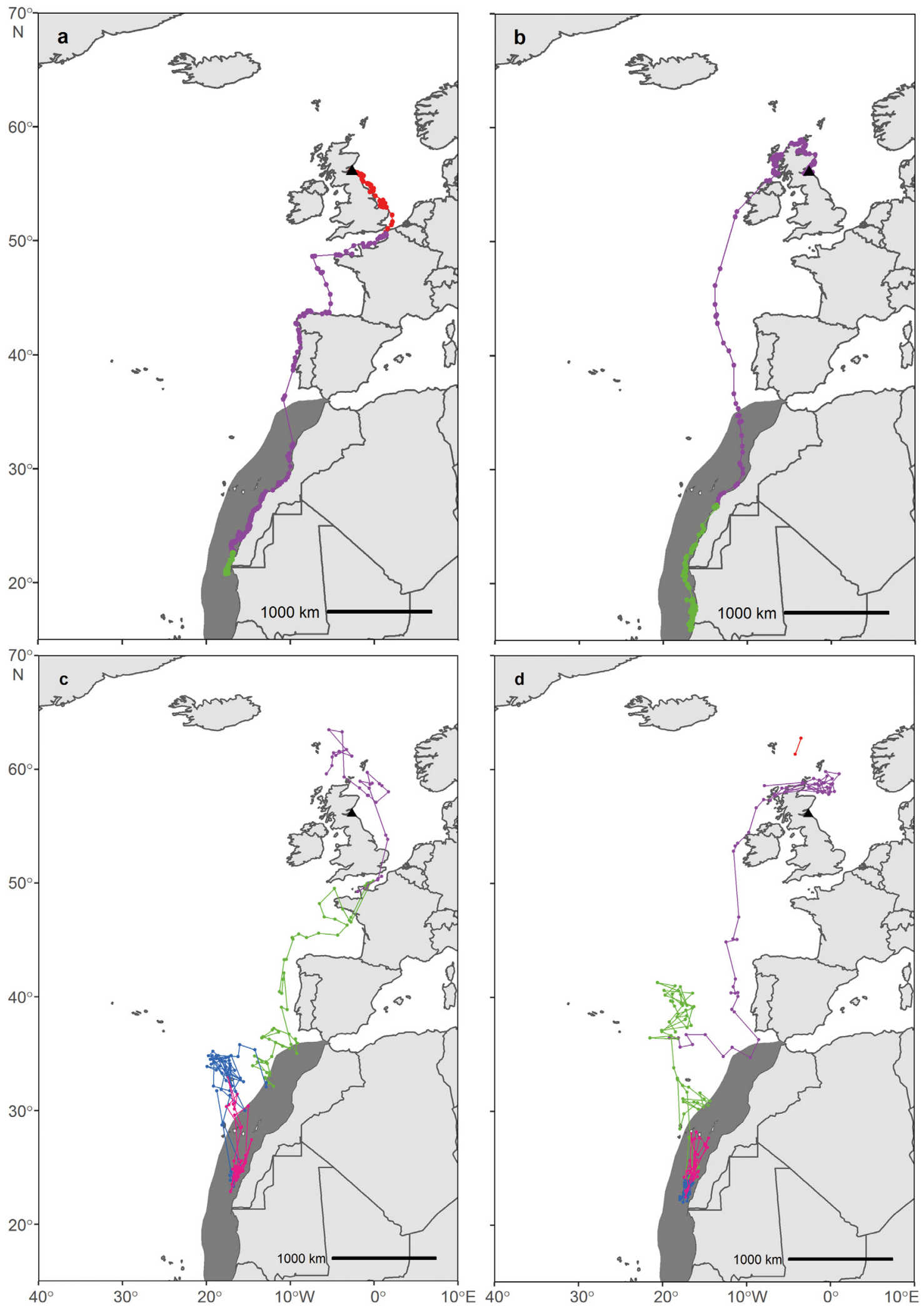

Fig. 2. Examples of $(a, c)$ clockwise and $(b, d)$ counter-clockwise migration routes of $(a, b)$ juvenile and $(c, d)$ adult gannets from Bass Rock. Locations coloured according to month: red $=$ September, purple $=$ October, green $=$ November, blue $=$ December, pink = January. Shaded area: Canary Current Large Marine Ecosystem, black triangle: Bass Rock 
Table 1. Mean (SD) migration summary for juvenile and adult gannets from Bass Rock, Scotland, travelling to the Strait of Gibraltar via the English Channel (clockwise) or via Scotland and the west coast of Ireland (counter-clockwise). Travel direction of 3 adults could not be determined

\begin{tabular}{|c|c|c|c|c|}
\hline & \multicolumn{2}{|r|}{018} & \multicolumn{2}{|c|}{$2019 \longrightarrow$} \\
\hline & Juveniles & Adults & Juveniles & Adults \\
\hline Birds (n) & 5 & 12 & 7 & 4 \\
\hline $\begin{array}{l}\text { Days to reach } \\
\text { Strait of Gibraltar }\end{array}$ & $27(12)$ & $54(19)$ & $18(7)$ & $112(16)$ \\
\hline Distance $(\mathrm{km}) \mathrm{d}^{-1}$ & $265.5(110.0)$ & $386.5(150.0)$ & $382.7(138.0)$ & $229.8(157.1)$ \\
\hline
\end{tabular}

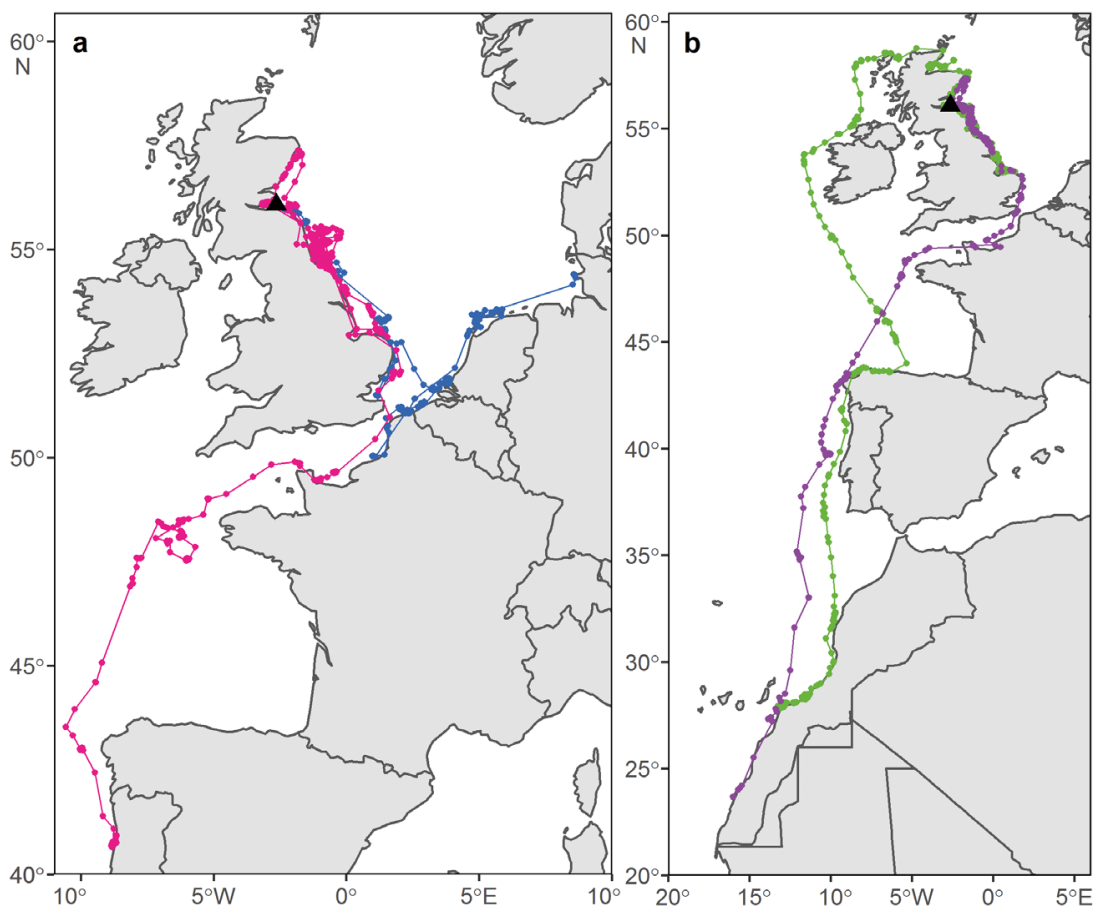

Fig. 3. Examples of juvenile gannets with non-monotonic travel. (a) Bird 1 (pink) travelled between the coasts of Aberdeenshire and Norfolk with several changes in direction over a period of $31 \mathrm{~d}$ before eventually heading southwards through the English Channel and dying on the North West coast of Portugal; Bird 2 (blue) initially travelled south along the North Sea coast to the Thames Estuary then made several changes in direction in the southern North Sea before travelling north along the Dutch coast to the Wadden Sea and dying on the North Frisian Coast. (b) Bird 3 (green) travelled $\sim 400 \mathrm{~km}$ south over $7 \mathrm{~d}$ to the north coast of Norfolk before making an about turn, returning to the colony over the next $9 \mathrm{~d}$ then continuing north to reach West Africa via the west coast of Ireland; Bird 4 (purple) headed north to Peterhead then reversed its direction of travel reaching West Africa via the English Channel. Tracks reconstructed using GPS and PTT locations. Black triangle: Bass Rock

abrupt changes in direction ( 1 of 16 individuals; $\chi^{2}$ using Fisher's exact test; $\chi^{2}{ }_{1}=7.4, p=0.01$ ).

\section{DISCUSSION}

The results of our study highlight the importance of the CCLME along the Atlantic coast of West Africa as a key destination for juvenile gannets migrating from Bass Rock. Our data reveal strong similarities between juveniles and adults in the large-scale pattern of migration, including the use of both clockwise and counter-clockwise routes around the UK and Ireland. However, there were also clear differences between age-classes in finer-scale movements and speeds of travel. These included marked and abrupt changes in the direction of travel of some juveniles within the North Sea, with potential implications for post-fledging survival and a marked restriction of juveniles to waters within $15 \mathrm{~km}$ of the coast throughout much of their migration and off West Africa, with implications for potential interactions with offshore wind farms and marine fisheries.

\subsection{Fledging, flight characteristics and mortality at sea}

A number of studies of seabirds have recorded a positive relationship between nestling body mass and postfledging survival (Perrins et al. 1973, Coulson \& Porter 1985, Dann 1988). In contrast, we recorded no such relationship, probably because most fledglings were in good condition when tagged (body mass of all but 5 birds exceeded the average adult body mass of $\sim 3 \mathrm{~kg}$; Table S1). In addition, large fat deposits may prevent birds from achieving the strength-to-weight ratio required to take off from the water surface (Montevecchi et al. 1984, Navarro 1992). In accordance with this notion, we found that aerial dispersal from the colony after fledging began only after a delay of up to $9 \mathrm{~d}$, during which time birds were drifting on the water, a similar period to that observed in juvenile wandering albatrosses Diomedea exulans (Weimerskirch et al. 2006). This delay, together with adverse effects of greater body mass on manoeuvrability and energy expenditure during flight (Amélineau et al. 2014), may result in a non-linear relationship or no relationship between pre-fledging body mass and sub- 
sequent survival, as reported in Atlantic puffins Fratercula arctica (Harris \& Rothery 1985) and shy albatrosses Thalassarche cauta (Alderman et al. 2010). Moreover, in wandering albatrosses, male chicks in poorer condition at fledging had higher subsequent survival, probably due to benefits of lower wing loading among young birds (Weimerskirch et al. 2000). In our study, once birds had become airborne from the sea, they increased their mean hourly displacement during daylight hours over the following 5-10 d, consistent with an increasing capacity for sustained flight. Thereafter, they travelled daily distances very similar to those of adults, suggesting that they acquired some components of flight capability relatively quickly, as also found in great frigatebirds Fregata minor (Corbeau et al. 2020) but in contrast to brown boobies Sula leucogaster, which have a long duration of post-fledging parental care during which they only gradually acquire efficient flight (Yoda et al. 2004).

About $60 \%$ of gannets die within their first year at sea (Wanless et al. 2006), and our satellite data suggest that a high proportion of this mortality occurs within a short period after fledging; almost one-third of juveniles died within 2 mo of leaving the colony, with over half of this mortality $(60 \%)$ occurring close to the colony within the first few days at sea. This pattern of mortality is similar to that found in ring recovery data; from 1600 birds ringed as chicks at Bass Rock, 589 birds (37\%) were found dead before the end of October of the same year (Table 23 in Nelson 2002). In our study, birds were sampled slightly after the peak of fledging in 2018, but there was no indication that this led to the selection of lower quality individuals, as post-fledging mortality was very similar in the 2 yr studied (Table S1), as were distances travelled per day (Table 1). High mortality during the first few months after attaining independence has also been recorded in several other species of seabird (Daunt et al. 2007, Guo et al. 2010, Afán et al. 2019). For instance, $49 \%$ of shy albatrosses satellite-tagged in Tasmania were assumed to have died within $5 \mathrm{~d}$ of fledging, probably due largely to foraging failure of naïve birds (Alderman et al. 2010).

High levels of post-fledging mortality emphasise the critical importance to juveniles of gaining proficiency in flight, foraging and navigational skills. In our study, juvenile mortality was often associated with uncertainties in the direction of migration, including marked, abrupt and often repeated changes in bearing within the North Sea. Such changes may have resulted from birds experiencing poor foraging success or encountering unfavourable wind conditions, potentially including both strong head winds that may have impeded progress (Lane et al. 2019) and light winds that may entail greater energy expenditure during flight in flap-gliding species such as gannets (Amélineau et al. 2014). Another possibility is that at least some juveniles followed adults, potentially allowing them to learn migration routes and foraging areas (Mueller et al. 2013), with some birds making inappropriate choices such as following adults still engaged in central-place foraging from the colony. Evidence for social learning in gannets has been recorded during the breeding season, when younger birds may follow more experienced birds to and from colonies (Wakefield et al. 2019). However, we found no indication of juveniles following adults on migration. Rather, adults departing at a similar time to juveniles headed mainly into the northern North Sea following the breeding season whereas juveniles travelled northwards and southwards mainly along the coast, probably using topography to aid their navigation (Pollonara et al. 2015). Moreover, abrupt changes in direction were not always associated with mortality, and juveniles may simply have been motivated to explore their natal area or search for foraging grounds before orienting to their migratory direction (Catry et al. 2011, Syposz et al. 2021).

\subsection{Characteristics of migration}

Of the 27 juveniles presumed not to have died before completing their migration, $44 \%$ were tracked to the CCLME and the remainder were travelling rapidly at intermediate locations between Bass Rock and the Strait of Gibraltar when their signal was lost. The CCLME is among the most productive marine ecosystems globally (Sambe et al. 2016) and is a key wintering ground for a suite of European seabirds (Camphuysen \& van der Meer 2005, GonzálezSolís et al. 2007, Grecian et al. 2016), including adult gannets (Grémillet et al. 2015, Grecian et al. 2019, this study). Our data highlight that it is also an important destination of juvenile gannets on their first migration. However, we also found that about onethird of adults did not migrate as far south as West Africa, in keeping with previous studies at this colony and elsewhere (Kubetzki et al. 2009, Grecian et al. 2016, Deakin et al. 2019, Grecian et al. 2019). This raises the possibility that some juveniles whose signal was lost north of Gibraltar may also have 
remained in European waters. This suggestion is supported to some extent by aerial survey data indicating the presence of young birds (aged 1-3 yr) in the Bay of Biscay over winter (Pettex et al. 2019), although the origin of these birds and the proportion of juveniles present were not known.

Although juveniles travelling to the Atlantic coast of West Africa moved a distance each day similar to that of adults, they reached the CCLME much more quickly than adults. It might have been expected that adults would migrate more quickly and efficiently than juveniles due to their greater age and experience (Thorup et al. 2003, Riotte-Lambert \& Weimerskirch 2013, de Grissac et al. 2016). However, the shorter journey times of juveniles in our study resulted mainly from them travelling more directly and staying close to the coast throughout most of their migration and off West Africa whereas adults additionally spent long periods (more than a month in some cases) over relatively restricted areas of ocean further offshore, particularly during October and November. This included time spent over the European continental shelf and deeper waters to the northeast of Bass Rock and over deep waters between the Atlantic coasts of Portugal and West Africa and the mid-Atlantic ridge, in areas of ocean with high productivity that are also visited over winter by a range of other species (Catry et al. 2011, Grecian et al. 2016) and by adult gannets from other European colonies (Fort et al. 2012). Hence, shorter journey times were probably due to juveniles having less flexibility than adults to explore offshore waters during their migration, possibly due to poorer knowledge of and experience with oceanographic conditions, poorer navigational skills or a benefit of less competition with adults (Votier et al. 2011, 2017, Grecian et al. 2018, Pettex et al. 2019). Wind speeds and wave heights increase with increasing distance from the Atlantic coast of West Africa (Semedo 2018), and so by staying close to the African coast, juveniles may also have avoided more taxing weather conditions further offshore.

Gannets from European populations face a number of potential threats during migration and over winter, including adverse interactions with offshore wind installations and marine fisheries. The southern North Sea holds the world's highest concentration of operational and planned offshore wind farms, presenting a potential risk to birds through both collision mortality and barrier effects (Furness et al. 2013, Garthe et al. 2017, Lane et al. 2020). Our data indicate that while both juveniles and adults migrate through this area in autumn, adults are potentially more likely to encounter wind turbines, as a result of apparently migrating further offshore, thus placing them at much greater risk than juveniles of adverse effects. In addition, our data indicate that both juvenile and adult gannets from Bass Rock winter within the CCLME, as also found in a small sample of birds tracked from a colony in the English Channel (Grémillet et al. 2015). This region experiences among the highest fishing effort globally and is a hotspot of illegal, unreported and unregulated fisheries, posing substantial threats to birds from depletion of prey stocks and both incidental and intentional bycatch in fishing gear (Laurans et al. 2004, Camphuysen \& van der Meer 2005, Agnew et al. 2009). Our data highlight the vulnerability of juveniles to these threats in addition to adults, as also found in Scopoli's shearwater (Afán et al. 2019). The impact of juvenile mortality on overall population size is less severe than that of adult mortality, but younger birds are more vulnerable to bycatch (Belda \& Sanchez 2001, Watkins et al. 2008) as well as being potentially more affected than adults by depletion of prey. Our findings highlight the importance of this region across different ageclasses of birds, echoing previous calls that the regional strengthening of marine conservation should be a high priority (Grémillet et al. 2015, Grecian et al. 2016, Afán et al. 2019).

Acknowledgements. This work was funded by the UK Government Department for Business, Energy \& Industrial Strategy (BEIS) Offshore Energy Strategic Environmental Assessment research programme and the Natural Environment Research Council (Industrial CASE studentship NE/P009387 $/ 1$ and 'SPHERES' DTP grant NE/L002574/1). We thank John Hartley (Hartley Anderson on behalf of BEIS) for support. We thank Sir Hew Hamilton-Dalrymple and the Scottish Seabird Centre, North Berwick for access to Bass Rock, Jack Dale and Sam Lowe for logistic support. Birds were ringed and loggers deployed with permits and approval from the British Trust for Ornithology. Telemetry data are available free of charge through the BirdLife International Seabird Tracking Database: www.seabirdtracking.org.

\section{LITERATURE CITED}

Afán I, Navarro J, Grémillet D, Coll M, Forero MG (2019) Maiden voyage into death: Are fisheries affecting seabird juvenile survival during the first days at sea? R Soc Open Sci 6:181151

Agnew DJ, Pearce J, Pramod G, Peatman T, Watson R, Beddington JR, Pitcher TJ (2009) Estimating the worldwide extent of illegal fishing. PLOS ONE 4:e4570

Alderman R, Gales R, Hobday AJ, Candy SG (2010) Postfledging survival and dispersal of shy albatross from three breeding colonies in Tasmania. Mar Ecol Prog Ser 405:271-285 
Alerstam T, Hedenstrom A, Akesson S (2003) Long-distance migration: evolution and determinants. Oikos 103: $247-260$

Amélineau F, Péron C, Lescroël A, Authier M, Provost P, Grémillet D (2014) Windscape and tortuosity shape the flight costs of northern gannets. J Exp Biol 217: 876-885

Argos (2016) Argos user's manual; worldwide tracking and environmental monitoring by satellite. www.argossystem.org/wp-content/uploads/2016/08/r363_9_argos_ users_manual-v1.6.6.pdf

Belda EJ, Sanchez A (2001) Seabird mortality on longline fisheries in the western Mediterranean: factors affecting bycatch and proposed mitigating measures. Biol Conserv 98:357-363

Bodey TW, Cleasby IR, Bell F, Parr N, Schultz A, Votier SC, Bearhop S (2018) A phylogenetically controlled metaanalysis of biologging device effects on birds: deleterious effects and a call for more standardized reporting of study data. Methods Ecol Evol 9:946-955

Borrmann RM, Phillips RA, Clay TA, Garthe S (2021) Postfledging migration and wintering strategies of individual juvenile lesser black-backed gulls (Larus fuscus). Ibis 163:1017-1031

Breed GA, Cameron MF, Ver Hoef JM, Boveng PL, Whiting A, Frost KJ (2018) Seasonal sea ice dynamics drive movement and migration of juvenile bearded seals Erignathus barbatus. Mar Ecol Prog Ser 600:223-237

Burnham KP, Anderson DR (2002) Model selection and multimodel inference: a practical information-theoretic approach. Springer, Berlin

Camphuysen CJ, van der Meer J (2005) Wintering seabirds in West Africa: foraging hotspots off Western Sahara and Mauritania driven by upwelling and fisheries. Afr J Mar Sci 27:427-437

* Catry P, Dias MP, Phillips RA, Granadeiro JP (2011) Different means to the same end: long-distance migrant seabirds from two colonies differ in behaviour, despite common wintering grounds. PLOS ONE 6:e26079

Charlesworth B (1980) Evolution in age-structured populations. Cambridge University Press, Cambridge

Cleasby IR, Wakefield ED, Bodey TW, Davies RD and others (2015) Sexual segregation in a wide-ranging marine predator is a consequence of habitat selection. Mar Ecol Prog Ser 518:1-12

Corbeau A, Prudor A, Kato A, Weimerskirch H (2020) Development of flight and foraging behaviour in a seabird with extreme soaring capacities. J Anim Ecol 89:20-28

Coulson JC, Porter JM (1985) Reproductive success in the Kittiwake Rissa tridactyla: the roles of clutch size, chick growth rates and parental quality. Ibis 127: 450-466

*Dann P (1988) An experimental manipulation of clutch size in the little penguin Eudyptula minor. Emu 88: 101-103

Daunt F, Afanasyev V, Adam A, Croxall JP, Wanless S (2007) From cradle to early grave: juvenile mortality in European shags Phalacrocorax aristotelis results from inadequate development of foraging proficiency. Biol Lett 3: 371-374

de Grissac S, Börger L, Guitteaud A, Weimerskirch H (2016) Contrasting movement strategies among juvenile albatrosses and petrels. Sci Rep 6:26103

Deakin Z, Hamer KC, Sherley RB, Bearhop S and others (2019) Sex differences in migration and demography of a wide-ranging seabird, the northern gannet. Mar Ecol Prog Ser 622:191-201

* Fort J, Pettex E, Tremblay Y, Lorentsen SH and others (2012) Meta-population evidence of oriented chain migration in northern gannets (Morus bassanus). Front Ecol Environ $10: 237-242$

Freitas C (2012) argosfilter: Argos locations filter. R package version 0.63. http://cran.r-project.org/package=argosfilter

*Furness RW, Wade HM, Masden EA (2013) Assessing vulnerability of marine bird populations to offshore wind farms. J Environ Manage 119:56-66

Furness RW, Garthe S, Trinder M, Matthiopoulos J, Wanless S, Jeglinski J (2018) Nocturnal flight activity of northern gannets Morus bassanus and implications for modelling collision risk at offshore wind farms. Environ Impact Assess Rev 73:1-6

Garthe S, Markones N, Corman AM (2017) Possible impacts of offshore wind farms on seabirds: a pilot study in northern gannets in the southern North Sea. J Ornithol 158: 345-349

* Genovart M, Oro D, Tenan S (2018) Immature survival, fertility and density dependence drive global population dynamics in a long-lived species. Ecology 99: 2823-2832

*González-Solís J, Croxall JP, Oro D, Ruiz X (2007) Transequatorial migration and mixing in the wintering areas of a pelagic seabird. Front Ecol Environ 5:297-301

Grecian WJ, Witt MJ, Attrill MJ, Bearhop S and others (2016) Seabird diversity hotspot linked to ocean productivity in the Canary Current Large Marine Ecosystem. Biol Lett 12:20160024

* Grecian WJ, Lane JV, Michelot T, Wade HM, Hamer KC (2018) Understanding the ontogeny of foraging behaviour: insights from combining marine predator biologging with satellite derived oceanography in hidden Markov models. J R Soc Interface 15:20180084

* Grecian WJ, Williams HJ, Votier SC, Bearhop S and others (2019) Individual spatial consistency and dietary flexibility in the migratory behavior of northern gannets wintering in the Northeast Atlantic. Front Ecol Evol 7:214

* Grémillet D, Péron C, Provost P, Lescroel A (2015) Adult and juvenile European seabirds at risk from marine plundering off West Africa. Biol Conserv 182:143-147

*Guo H, Cao L, Peng L, Zhao G, Tang S (2010) Parental care, development of foraging skills, and the transition to independence in the red-footed booby. Condor 112: $38-47$

Hamer KC, Phillips RA, Wanless S, Harris MP, Wood AG (2000) Foraging ranges, diets and feeding locations of gannets Morus bassanus in the North Sea: evidence from satellite telemetry. Mar Ecol Prog Ser 200:257-264

* Harris MP, Rothery P (1985) The post-fledging survival of young puffins Fratercula arctica in relation to hatching date and growth. Ibis 127:243-250

*Hazen EL, Maxwell SM, Bailey H, Bograd SJ and others (2012) Ontogeny in marine tagging and tracking science: technologies and data gaps. Mar Ecol Prog Ser 457: 221-240

*Kubetzki U, Garthe S, Fifield D, Mendel B, Furness RW (2009) Individual migratory schedules and wintering areas of northern gannets. Mar Ecol Prog Ser 391: 257-265

* Lane JV, Spracklen DV, Hamer KC (2019) Effects of windscape on three-dimensional foraging behaviour in a 
wide-ranging marine predator, the northern gannet. Mar Ecol Prog Ser 628:183-193

Lane JV, Jeavons R, Deakin Z, Sherley RB, Pollock CJ, Wanless RJ, Hamer KC (2020) Vulnerability of northern gannets to offshore windfarms; seasonal and sex-specific collision risk and demographic consequences. Mar Environ Res 162

Langston RHW, Teuten E, Butler A (2013) Foraging ranges of northern gannets Morus bassanus in relation to proposed offshore wind farms in the UK 2010-2012. RSPB Report to DECC. https://assets.publishing.service.gov. uk/government/uploads/system/uploads/attachment_ data/file/406991/OESEA2_North_Sea_Gannet_Tracking _Year3_Report.pdf

Laurans M, Gascuel D, Chassot E, Thiam D (2004) Changes in the trophic structure of fish demersal communities in West Africa in the three last decades. Aquat Living Resour 17:163-173

Lisovski S, Hahn S (2012) GeoLight-processing and analysing light-based geolocator data in R. Methods Ecol Evol 3:1055-1059

Merkel B, Phillips RA, Descamps S, Yoccoz NG, Moe B, Strøm H (2016) A probabilistic algorithm to process geolocation data. Mov Ecol 4:26

* Miller TA, Brook RP, Lanzone MJ, Brandes D and others (2016) Limitations and mechanisms influencing the migratory performance of soaring birds. Ibis 158: 116-134

Montevecchi WA, Ricklefs RE, Kirkham IR, Gabaldon D (1984) Growth energetics of nestling northern gannets (Sula bassanus). Auk 101:334-341

Mueller T, O'Hara RB, Converse SJ, Urbanek RP, Fagan WF (2013) Social learning of migratory performance. Science 341:999-1002

Murray S, Wanless S, Harris M (2014) The Bass Rock — now the world's largest northern gannet colony. Br Birds 107: 769-770

Navarro R (1992) Body compositions, fat reserves and fasting capability of Cape gannet chicks. Wilson Bull 104: 644-655

Nelson B (2002) The Atlantic gannet. T \& AD Poyser, London

* Péron C, Grémillet D (2013) Tracking through life stages: adult, immature and juvenile autumn migration in a long-lived seabird. PLOS ONE 8:e72713

Perrins CM, Harris MP, Britton CK (1973) Survival of the Manx shearwater Puffinus puffinus. Ibis 115: 535-548

Pettex E, Lambert C, Fort J, Dorémus G, Ridoux V (2019) Spatial segregation between immatures and adults in a pelagic seabird suggests age-related competition. J Avian Biol 50:e01935

Phillips RA, Xavier JC, Croxall JP (2003) Effects of satellite transmitters on albatrosses and petrels. Auk 120: 1082-1090

Physical Sciences Division (2019) NOAA high resolution SST data. https://psl.noaa.gov/data/gridded/data.noaa. oisst.v2.highres.html (accessed on 9 December 2020)

Pinheiro J, Bates D, DebRoy S, Sarkar D and others (2018) nlme: linear and nonlinear mixed effects models. R package version 3.1-119. https://cran.r-project.org/package= nlme

Pollonara E, Luschi P, Guilford T, Wikelski M, Bonadonna F, Gagliardo A (2015) Olfaction and topography, but not magnetic cues, control navigation in a pelagic seabird: displacements with shearwaters in the Mediterranean Sea. Sci Rep 5:16486

R Core Team (2016) R: a language and environment for statistical computing. R Foundation for Statistical Computing, Vienna

Reynolds RW, Smith TM, Liu C, Chelton DB, Casey KS, Schlax MG (2007) Daily high-resolution-blended analyses for sea surface temperature. J Clim 20:5473-5496

* Riotte-Lambert L, Weimerskirch H (2013) Do naive juvenile seabirds forage differently from adults? Proc Biol Sci 280: 20131434

* Rotics S, Kaatz M, Resheff YS, Feldman Turjeman S and others (2016) The challenges of the first migration: movement and behaviour of juvenile vs. adult white storks with insights regarding juvenile mortality. J Anim Ecol 85:938-947

* Sambe B, Tandstad M, Caramelo AM, Brown BE (2016) Variations in productivity of the Canary Current Large Marine Ecosystem and their effects on small pelagic fish stocks. Environ Dev 17:105-117

Semedo A (2018) Seasonal variability of wind sea and swell waves climate along the Canary Current: the local wind effect. J Mar Sci Eng 6:28

Sergio F, Tavecchia G, Tanferna A, Blas J, Blanco G, Hiraldo F (2019) When and where mortality occurs throughout the annual cycle changes with age in a migratory bird: individual vs population implications. Sci Rep 9:17352

Spiegel CS, Berlin AM, Gilbert AT, Gray CO and others (2017) Determining fine-scale use and movement patterns of diving bird species in federal waters of the midAtlantic United States using satellite telemetry. OCS Study BOEM 2017-069. U.S. Department of the Interior, Bureau of Ocean Energy Management, Sterling, VA

Stearns SC (1992) The evolution of life histories. Oxford University Press, Oxford

* Sullivan KA (1989) Predation and starvation: age-specific mortality in juvenile juncos (Junco phaenotus). J Anim Ecol 58:275-286

* Syposz M, Padget O, Wynn J, Gillies N, Fayett AL, Guilford $\mathrm{T}$ (2021) An assay to investigate factors influencing initial orientation in nocturnally fledging seabirds. J Avian Biol 52:02613

* Thorup K, Alerstam T, Hake M, Kjellén N (2003) Bird orientation: compensation for wind drift in migrating raptors is age dependent. Proc Biol Sci 270:S8-S11

*Votier SC, Grecian WJ, Patrick S, Newton J (2011) Intercolony movements, at-sea behaviour and foraging in an immature seabird: results from GPS-PPT tracking, radiotracking and stable isotope analysis. Mar Biol 158: 355-362

Votier SC, Fayet AL, Bearhop S, Bodey TW and others (2017) Effects of age and reproductive status on individual foraging site fidelity in a long-lived marine predator. Proc Biol Sci 284:1859

* Wakefield ED, Bodey TW, Bearhop S, Blackburn J and others (2013) Space partitioning without territoriality in gannets. Science 341:68-70

*Wakefield ED, Cleasby IR, Bearhop S, Bodey TW and others (2015) Long-term individual foraging site fidelity - why some gannets don't change their spots. Ecology 96: 3058-3074

WWakefield ED, Furness RW, Lane JV, Jeglinski JWE, Pinder S (2019) Immature gannets follow adults in commuting flocks providing a potential mechanism for social learning. J Avian Biol 50:02164 
Wanless S, Okill JD (1994) Body measurements and flight performance of adult and juvenile gannets Morus bassanus. Ring Migr 15:101-103

Wanless S, Frederiksen M, Harris MP, Freeman SN (2006) Survival of gannets Morus bassanus in Britain and Ireland, 1959-2002. Bird Study 53:79-85

Watkins BP, Petersen SL, Ryan PG (2008) Interactions between seabirds and deep-water hake trawl gear: an assessment of impacts in South African waters. Anim Conserv 11:247-254

Editorial responsibility: Rory Wilson,

Swansea, UK

Reviewed by: D. G. Bennet and 2 anonymous referees
Weimerskirch H, Barbraud C, Lys P (2000) Sex differences in parental investment and chick growth in wandering albatrosses: fitness consequences. Ecology 81:309-318

Weimerskirch H, Åkesson S, Pinaud D (2006) Postnatal dispersal of wandering albatrosses Diomedea exulans: implications for the conservation of the species. J Avian Biol 37:23-28

Yoda K, Kohno H, Naito Y (2004) Development of flight performance in the brown booby. Proc R Soc B 271(Suppl 4): S240-242

Submitted: April 30, 2020

Accepted: June 23, 2020

Proofs received from author(s): July 28, 2021 